\title{
Conselho Municipal de Saúde: (re)pensando a lacuna entre $o$ formato institucional e o espaço de participação social
}

\author{
Municipal Health Council: (re)thinking the gap between \\ the institutional pattern and the space of social participation
}

Rosângela M inardi M itre Cotta ${ }^{1}$

M ariana de $M$ elo Cazal ${ }^{1}$

Poliana Cardoso $M$ artins ${ }^{2}$

${ }^{1}$ Departamento de Nutrição eSaúde, Universidade Federal deViç̧osa. Av. PH Rolfs $s / n$, Campus Universitário. 35570-000 Viçosa M G. rmmitre@ufv.br

${ }^{2}$ Instituto Multidisciplinar em Saúde, Universidade Federal da Bahia.
Abstract Thepresent essay is involved in the construction of the participation of civil society organized in health as a citizenship exercise and the place of $\mathrm{M}$ unicipal $\mathrm{H}$ ealth Council ( $\mathrm{M} \mathrm{HC}$ ) in this participation process. The study has as objective to analyze the institutional pattern of the $\mathrm{M} \mathrm{HC}$ of Viçosa, M inas Gerais State, approaching thestructure and operation dynamics, composition rules and competences. It is related to the observational study of traverse stamp, where individual interviews with the counselors of health, non participative direct observation of meetings of the $\mathrm{M} \mathrm{HC}$ and documents were used as instrument of analysis. A number of 34 members $(77,2 \%)$ of the re spective council were interviewed. Among the results, it stands out that $44,2 \%$ of the interviewed said that the decisions taken in the M HC are not informed to the population and $35,3 \%$ does not transfer the information of the proposals and discussions taken in the M HC for discussion and deliberation for their pairs. For the documental analysis, it was verified that the composition of the MHC of Viçosa is not in agreement with the foreseen distribution by the federal legislation. The results suggest the existence of problems related to the representation, limiting the social participation in the councils.

Key words Social participation, Municipal H ealth Council, Social control, Brazilian Unified $\mathrm{H}$ ealth System
Resumo 0 presentetrabal ho inscreve se no contexto da construção da participação da sociedade civil organizada em saúde como exercício da cidadania e do espaço dos Conselhos M unicipais de Saúde (CMS) neste processo de participação. 0 estudo tem por objetivo analisar o formato institucional do CM S deV içosa (M G), abordando sua estrutura e dinâmica de funcionamento, regras de composição e competências. Trata-se de um estudo observacional de cunho transversal, no qual se utilizou como instrumentos de análises entrevistas individuais dirigidas aos consel heiros de saúde, observação direta não participativa das reuniões do CM S e análise documental. Dos 34 membros entrevistados $(77,2 \%$ dos membros do CM S), 44,2\% afirmaram que as decisõestomadas no CM $S$ não são informadasà população e 35,3\% não repassam as informações sobre as propostas e discussões tomadas no CM S para discussão edeliberação por seus pares. Pela análise documental, constatou-se que a composição do CM S de Viçosa, na gestão estudada, não está de acordo com a distribuição prevista pela legislação federal. Os resultados sugerem a existência de problemas re lacionados à representação, limitando a participação social no conselho.

Palavras-chave Participação social, Conselho M unicipal deSaúde, Controlesocial, Sistema Ú nico de Saúde 
Introdução

No Brasil, a reforma da política de saúde deve ser compreendida a partir da questão mais ampla da descentralização e democratização do Estado, a qual se inscreve no contexto das reformas sociais iniciadas a partir da segunda metade da década de setenta ${ }^{1}$.

A transição política do regime militar para uma democracia participativa gerou uma abertura política impulsionada pela pressão da sociedade civil, através da força dos movimentos sociais, que se diferenciam por expressar fortes conteúdos reivindicativos e de oposição ao regime militar, tendo a liberdade política como 0 ponto de partida da mobilização social2,3.

A busca de uma vida com mais saúde, educação, moradia, saneamento, renda e a crescente perda da qualidade de vida, diante da falta destes bens, ocasionou um "caráter" de oposição e reivindicação por mudanças na estrutura social, econômica e política do país. Diante desta realidade, as políticas sociais adquiriram o sentido de instrumento de justiça social e se tornaram o fio transmissor entre a sociedade e o Estado, até então omisso. N este período, a interdição do Estado torna-se insuficiente para controlar a ação coletiva destes novos atores, criando possibilidades para que os movimentos sociais passem a se articular enquanto organismos políticos de representação da sociedade ${ }^{1,2}$.

Não obstante, a transição para a democracia assume características peculiares, em que uma descompressão planejada abre espaços para coalizões heterogêneas, resultando no que Cotta et al. ${ }^{1}$ denominaram "pacto interelites". Para os diversos atores sociais envolvidos neste "pacto" (burocracia pública e áreas profissionais e intelectuais) , a descentralização ea instituição de práticas participativas constituíram estratégias fundamentais para a implementação das reformas do Estado ${ }^{1}$.

Pode-se considerar como um marco deste período a realização da VIII Conferência Nacional de Saúde(VIII CNS) no ano de 1986, na qual a participação ativa de diversos segmentos da sociedade abriu a possibilidade para um modelo de política de saúde mais democrático ${ }^{4}$.

Desse modo, a Constituição Federal de 1988, em seus artigos, 196 a 200, incorporou as propostas originais da reforma sanitária, sintetizadas na VIII CNS, na forma do Sistema Ú nico de Saúde (SUS). O SUS é regulamentado pelas Leis Orgânicas da Saúde8.080/90 e 8.142/90, nas quais encontra o detal hamento de suas diretrizes e da operacionalização de alguns aspectos do sistema. As Normas de O peração Básica (NOB), Normas de Assistência à Saúde (NOAS), o Pacto pela Saúde e demais portarias e resoluções do M inistério da Saúde complementam, organizam e definem as balizas para implementação da política de saúde em nosso país. Assim, com o SUS, a saúde emerge como questão de cidadania e a participação social como condição essencial para o seu exercício $0^{1,5}$.

A institucionalização da participação social no SUS foi feita por meio de vários dispositivos legais, a começar pelo texto constitucional de 1988, que define o "caráter democrático edescentralizado da gestão administrativa, com a participação da comunidade" ${ }^{\prime}$.

Assim, no setor saúde, a participação social passa a ser um dos princípios orientadores do SUS, constituindo, para sua concretização, a criação dos novos canais participativos, nas três esferas de governo - consel hos e conferências de saúde - sendo os Conselhos de Saúde os principais órgãos de controle social na definição do sistema e dos serviços de saúde7.

Em 1991, ésancionada a Lei 8.142, quedefine a competência dos Conselhos de Saúde: art. $1^{\circ}$, parágrafo 2०: 0 Conselho de Saúde, em caráter permanente e deliberativo, órgão colegiado composto por representantes do governo, prestadores de serviço, profissionais de saúde e usuários, atua na formulação de estratégi as e no controle da execução da política de saúdena instância correspondente, inclusive nos aspectos econômicos e financeiros, cujas decisões serão homol ogadas pelo chefe do poder legalmente constituído em cada esfera do governo ${ }^{8}$.

Desde esta perspectiva, vale salientar que os conselhos de saúde constituem-se como novos espaços públicos propiciados pela reestruturação do Estado, obtida pelas forças políticas com base no pressuposto de que a participação da sociedade deva ser acolhida pelo Estado como forma de controlesocial einterferência na definição e desempenho das políticas públicas. Assim, com a criação dos conselhos, o controle social assume lugar estratégico na definição e execução das políticas de saúde no Brasi ${ }^{5,9}$.

Considerando que a participação e o exercício do controle social realizados pelos consel hos desaúdeocorrem em espaço público, esse exercício tem como contrapartida fundamental a ideia de que a visibilidade e o compartilhamento do que é público devem ser baseados na premissa de que tudo o que vem a público pode ser ouvido, visto e comentado por todos ${ }^{10}$. Sem visibili- 
dade e compartilhamento, não há ação pública ou projeto político, porque ser visto e ouvido pluralmente pelos outros éuma forma de direcionar a ação social e constituir a realidade.

Tendo como base essas premissas, este estudo tem por objetivo analisar o formato institucional do CMS de Viçosa (MG), abordando sua estrutura, dinâmica defuncionamento, regras de composição e competências. Pese a que o formato institucional não explique como se dão as disputas e negociações internas, pode determinar o significado dos conselhos e a possibilidade destas instituições ampliarem os espaços de participação social.

\section{Metodologia}

Trata-se de um estudo observacional de corte transversal, fundamentado pelo referencial térico da pesquisa qualitativa em saúde, no qual foram utilizados três instrumentos de investigação: entrevistas semiestruturadas, realizadas por um único entrevistador devidamente treinado, durante o período de abril a julho de 2006, observação direta, não participativa, das reuniões do CM S e análise documental.

Criou-se um questionário, dirigido aos consel heiros desaúde, especificamente para esta pesquisa, que abrangia as seguintes dimensões: te máticas discutidas nas reuniões do CM S, prioridades dos temas discutidos, divulgação das informações, periodicidade das reuniões, recebimento prévio da pauta de reunião, acompanhamento do relatório de gestão e implementação das deliberações do CMS. As entrevistas foram gravadas e realizadas em local definido previamente pelos próprios conselheiros.

Em relação à análise documental, foram avaliados os seguintes documentos do município: regimento interno do $\mathrm{CMS}$, plano municipal de saúde e relatório de gestão.

0 estudo foi realizado no município de Viçosa, situado na Zona da M ata de Minas Gerais, localizado a 152,9 quilômetros de Belo H orizonte. A população residenteé de 64.910 , sendo que, destes, 59.896 (92,27\%) moram na zona urbana e 5.014 (7,73\%), na zona rural, segundo o último censo demográfico realizado em 2000, pelo Instituto Brasileiro de Geografia eEstatística ${ }^{11}$. Possui uma área territorial de $300,2 \mathrm{~km}^{2}$, densidade demográfica de $216,2 \mathrm{hab} . / \mathrm{km}^{2}$ e uma altitude de 648 metros. A principal ocupação econômica da população concentra-se no setor de serviços. Quanto ao Índice de Desenvolvimento H umano
(IDH ), o município apresentaum desenvolvimento relativamente alto, com índice acima de $0,8^{12}$.

Desde sua implantação, em 1991, o CM S do município estudado éformado por 44 membros, sendo 22 titulares e seus respectivos suplentes. Participaram do estudo 34 (77,2\%) conselheiros da gestão atual do CM S; dos dez (22,73\%) conselheiros que não participaram do estudo, dois $(4,56 \%)$ serecusaram a participar, cinco $(11,4 \%)$ não foram encontrados e os cargos de três estavam vagos $(6,83 \%)$. Todos os indivíduos queaceitaram participar do estudo assinaram um termo de consentimento livreesclarecido.

Os dados coletados foram digitados e analisados no SPSS versão 11.5, com auxílio do programa M icrosoft Excel 2003.

\section{Resultados}

Dos 34 conselheiros de saúde entrevistados, dezenove $(55,9 \%)$ eram do sexo masculino equinze $(44,1 \%)$, do sexo feminino, com média deidade de 46,82 anos, variando de 22 a 69 anos. No que se refereà renda familiar dos consel heiros, a média encontrada foi de 8,03 salários mínimos (SM ), variando de um a quarenta SM , e, em relação à escolaridade, a maioria dos entrevistados, 21 conselheiros $(61,8 \%)$, tinha nível superior completo.

A composição do conselho não obedece às recomendações dalegis lação vigente, segundo as quais o princípio da paridade deve ser respeitado, isso é, $50 \%$ das vagas ocupadas por representantes dos usuários e os outros $50 \%$ de vagas divididas da seguinte forma: $25 \%$ para entidades dos trabalhadores de saúde e, $25 \%$ para representantes de governo, de prestadores de serviços privados conveniados ou sem fins lucrativos ${ }^{13}$. A realidadeencontrada retrata uma incoerência entre a proporção de representantes dos profissionais da saúde, uma vez quea distribuição dos conselheiros apresentaa seguinte proporção: $50 \%$ dos consel heiros são representantes dos usuários; $22,7 \%$, do governo municipal; $18,2 \%$, de prestadores de serviço; $9 \%$, de representantes dos profissionais de saúde.

Segundo $97,1 \%$ dos conselheiros, as reuniões do CM S ocorrem mensalmente, sendo que 2,9\% não souberam responder sobre a periodicidade das reuniões. De acordo com o regimento interno do CMS, o Secretário Municipal de Saúde (SM S) é membro nato do mesmo, sendo também o responsável pela presidência do órgão.

Sobre os temas abordados nas reuniões, $44,1 \%$ dos consel heiros destacaram a diversida- 
de de temas discutidos, abordando desde promoção da saúde até a prestação de contas; $23,5 \%$ disseram que são todos os assuntos referentes às ações eserviços de saúde; $29,4 \%$ responderam de forma vaga, informando que são discutidos assuntos relacionados à saúde e de relevância para o município, não sabendo citar exemplos dos temas discutidos quando solicitados; e2,9\% afirmaram que são assuntos de interesse da presidência do conselho, ou seja, do SM S.

Em relação à prioridade de assuntos discutidos nas reuniões do CM S, estes são determinados pelo SM S, segundo doze (35,3\%) dos entrevistados; para onze (32,4\%), além do SMS, os conselheiros também determinam prioridades dos temas; quatro (11,8\%) afirmam que as prioridades dos temas são determinadas apenas pelos consel heiros, sem interferência do SM S; cinco $(14,6 \%)$ informaram que ostemasquecompõem a pauta do conselho são definidostanto pelo SMS, quanto pelos consel heiros, tendo como referência a urgência dos mesmo; edois (5,9\%) dos conselheiros não souberam responder.

$\mathrm{Na}$ Tabela 1, pode-se visualizar algumas características de funcionamento ecompetências do CM S analisado. Em relação ao período de tem-

Tabela 1. Características do funcionamento e das competências do Conselho Municipal de Saúde. Viçosa (MG), 2006.

\begin{tabular}{lrr}
\hline \multicolumn{1}{c}{ Variáveis } & $\mathrm{n}$ & $\%$ \\
\hline Período de tempo do recebimento & & \\
prévio das pautas de reuniões do CMS & & \\
1 a 3 dias & 3 & 8,87 \\
4 a 7 dias & 24 & 0,61 \\
8 a 11 dias & 5 & 4,7 \\
12 ou mais dias & 2 & 5,9 \\
Divulgação paraa população das decisões & & \\
tomadas no CMS & & \\
Não sei & 1 & 2,92 \\
São divulgadas & 8 & 3,52 \\
Pouco divulgadas & 10 & 9,4 \\
Não são divulgadas & 15 & 44,2 \\
Efetivação das deliberações do CMS & & \\
M inoria & 2 & 5,9 \\
M etade & 1 & 2,9 \\
Algumas & 8 & 23,5 \\
M aioria & 5 & 14,7 \\
Todas & 14 & 41,2 \\
Não sei & 4 & 11,8 \\
Total & 34 & 100,0 \\
\hline
\end{tabular}

po de antecedência de recebimento das pautas das reuniões do CMS, nota-se que 70,6 \% dos conselheiros relataram receber as atas com quatro a sete dias de antecedência.

Em relação à divulgação das decisões tomadas no CMS, 44,2\% afirmaram que estas não são informadas à população. Sobre a implantação das deliberações tomadas pelos conselheiros duranteas assembléias, quatro (11,8\%) dosmesmos não souberam responder se as deliberações do CM S são efetivadas e trinta ( $88,2 \%$ ) afirmaram que as deliberações tomadas nas reuniões do CMS são implantadas (Tabela 1).

Quando interrogados sobre o meio utilizado para afirmar que as deliberações tomadas no CM S são efetivadas na prática, doze (40\%) e seis (20\%) dos entrevistados obtinham esse conhecimento por meio deinformações do SM S nas reuniões do CM S e da comunidade, respectivamente. Vale ressaltar que apenas cinco $(16,6 \%)$ disseram que utilizam a fiscalização em serviços de saúde para afirmar que as deliberações tomadas no CMS são implantadas (Tabela 2).

No que diz respeito ao repasse das informações pelos conselheiros das propostas e discussões tomadas no CMS para seus pares, 35,3\% dos consel heiros entrevistados disseram que não as repassam.

Sobre a forma de ingresso no CM S, 38, $2 \%$ foram eleitos por seus pares, $8,8 \%$ foram convocados por serem os presidentes das entidades que representam no CM S e 52,9\% foram indicados; dentre estesúltimos, 32,4\% foram indicados pela diretoria da instituição, 8,8\%, pelo titular, 8,8\%, pelo prefeito e2,9\%, pela Secretaria Municipal de Saúde.

Tabela 2. Distribuição dos principais meios usados pelos consel heiros para afirmar que as deliberações tomadas no CMS são implantadas. Viçosa (M G), 2006.

\begin{tabular}{lcr}
\hline \multicolumn{1}{c}{ M eios } & n & $\%$ \\
\hline $\begin{array}{l}\text { Por informação do SM S durante as } \\
\text { reuniões do CM S e fiscalização nos }\end{array}$ & 2 & 6,7 \\
serviços de saúde & & \\
Por divulgação da imprensa & 2 & 6,7 \\
Por informação dos outros conselheiros & 3 & 10 \\
Por fiscalização nos serviços de saúde & 5 & 16,6 \\
Por informação da comunidade & 6 & 20 \\
Por informação do SM S durante as & 12 & 40 \\
reuniões do CM S & & \\
Total & 30 & 100,0
\end{tabular}


Quanto ao envio do relatório de gestão pelo SM S para avaliação e aprovação pelo CM S, 50\% dos conselheiros não souberam informar se este é avaliado todos anos ao CM S; já $29,4 \%$ afirmaram que não é enviado e 20,6\% afirmam que o relatório degestão éenviado anualmenteao CMS para avaliação e aprovação do mesmo.

\section{Discussão}

Os resultados do presente estudo apontam para o fato de que a composição do CM S de Viçosa, na gestão estudada, não está de acordo com a distribuição prevista pela legislação federal. Verificou-se que, apesar de garantida a paridade na representação dos usuários em relação aos de mais segmentos, tem-se uma inadequação na representação dos profissionais de saúde (9\%), uma vez que o percentual definido pela Resolução n 333/2003 do Conselho N acional de Saúde éde $25 \%$ dos consel heiros ${ }^{13}$. Já os representantes do governo e prestadores de serviços ocupavam $41 \%$ das vagas do CMS, mas deveriam ocupar apenas $25 \%$ das vagas.

Os dados encontrados vão ao encontro dos resultados apresentados por Stralen et al. ${ }^{14}$, em estudo que objetivava avaliar a efetividade do controle social em municípios dos estados de Goiás e M ato Grosso do Sul. Estes autores observaram também uma subrrepresentação dos profissionais de saúde (abaixo de $25 \%$ dos conselheiros) em três conselhos estudados, sugerindo que a permanência dessa subrrepresentação pode estar ligada à ausência ou a falta de mobilização dos órgãos de classe.

Em consonância com a realidade estudada, se faz imprescindível questionar a efetividade de atuação e representatividade dos interesses dos diversos segmentos sociais no CM S. Lembrando que, dentre as competências do poder executivo no processo de criação e reformulação dos conselhos, respeitando-se os princípios da democracia, estedeve garantir condi ções para a participação efetiva de todos os segmentos sociais na avaliação e controle das políticas de saúde. Assim, fica difícil pensar que a verdadeira participação possa ocorrer, diante do não cumprimento legal da forma de composição do CM S, fortalecendo algumas categorias em detrimento de outras 4 .

Esse dado aponta para um aumento da influência de poder do governo e dos prestadores de serviços no CM S, o que pode privilegiar o setor privado em detrimento do setor público, ou aindatransformar a municipal ização em seu efei- to indesejável da "prefeiturização", situação predominante de hegemonia, em que a dominação política exercida pelo executivo decorre de relações patrimonialistas ou de algum tipo de liderança carismática ${ }^{1,2}$.

Outro ponto que pode reforçar essa influência de um segmento específico nas deliberações do CM Séo fato de ser definido em seu regimento interno (1991) queo SM S, como membro nato do CM S, deve exercer a função de presidente do mesmo. Stralen et al. ${ }^{14}$, analisando a presidência dos CM S estudados, encontraram que cinco dos nove municípios pesquisados tinham também 0 SM S como presidente dos consel hos. A permanência do SM S como presidente do conselho pode assinalar uma possível restrição da autonomia do CM S, sendo o próprio SM S que delibera e homologa as decisões tomadas neste.

Não obstante, ao se considerar os assuntos tratados nas reuniões do CMS, um ponto importante a ser avaliado é 0 ator responsável pela definição da pauta das reuniões. Observa-se que a maioria dos consel heiros (35,3\%) relatou que a prioridade de assuntos é definida pelo SM $\mathrm{S}^{15}$.

Destarte, através destas regularidades organizacionais, pretende-se colocar em questão 0 grau de democratização interno das organizações de saúde, que demarca o fluxo do processo decisório e o grau de influência de cada instância ou unidade de organização na gestão institucional. Estefato émuitas vezes criticado por permitir a manipulação dos interesses dos representantes do governo municipal sobre os demais segmentos, tornando a representação destes outros segmentos ineficaz, o que pode se agravar quando a representação entre as diferentes categorias é desigual, conforme encontrado no presente estudo.

Quanto à divulgação das deliberações do CM S, $44,1 \%$ dos entrevistados afirmaram que estas não são informadas à população, desobedecendo a Resolução n 333/2003, que define como competência dos conselhos estabelecer ações de informação, educação e comunicação em saúde e divulgar as funções e competências do Conselho de Saúde, seus trabalhos e decisões para todos os meios de comunicação, incluindo informações sobre as agendas, datas e local das reuniões ${ }^{13}$. A visibilidade dos conselhos éum ponto crucial para 0 exercício do controle social, caracterizando-se pela transparência das ações, na criação de canais de comunicação com a população.

Democratizar as informações e permitir sua avaliação por parte dos usuários seria colocar o usuário no centro do processo, numa relação de 
corresponsabilidade. $M$ as, para que essa gestão partici pativa aconteça, torna-senecessário a existência de canais de participação desobstruídos e fluxo constantedeinformações. Requer, também, processos que favoreçam a participação ativa, representativa, autônoma e corresponsável, que propiciem, demodo mais completo, o crescimento das pessoas ou das organizações coletivas?.

Vale salientar a importância de canais de comunicação e instrumentos que possibilitem a democratização da informação, como cartilhas, boletins informativos, jornais, entre outros, garantindo maior visibilidade dos consel hos de saúde ${ }^{16}$. Entretanto, não se pode esquecer que a existência dealguma forma dedivulgação não significa quea população eentidades civistenham conhecimento das decisões e discussões dos conselhos ${ }^{14}$.

A publicização das decisões tomadas é fundamental, porque indica comprometimento e responsabilidade dos conselhos; além disso, essa é uma etapa que assegura a confiabilidade nos mecanismos participativosetambém cumpreum papel educativo junto à população, porque mostra a possibilidade da real efetivação da participação da sociedade civil na gestão compartilhada de políticas públicas; é a atuação dos grupos, movimentos e outros coletivos organizados como sujeitos coletivos na esfera pública o que fortalecea sociedade civil ea sociedade política ${ }^{17}$.

Estudo realizado por $\mathrm{M}$ artins ${ }^{18}$ observou que a maioria dos usuários do SUS $(94,1 \%)$, residentes em um município vizinho à Viçosa, não conheciam o CM S. Assim, pode-se ressaltar que o conselho pode até ser uma instituição muito valorizada por aqueles que dele participam, mas é desconhecido por grande parte dos cidadãos.

Segundo Westphal ${ }^{19}$, um dos grandes problemas da participação nos CM S é a representatividade. Muitos representantes comparecem ao órgão colegiado sem consultar suas bases, falando em seu nome e não em nome do grupo, e muito menos compartilham as decisões tomadas nas reuniões com seus pares. A baixa repre sentatividade das lideranças revela-se, portanto, um elemento essencial para a compreensão da fragilidade de certas instâncias. No entanto, caberia explorar o papel que a participação nestas instâncias, dentre outros mecanismos, pode desempenhar no processo de capacitação desses atores para a negociação, junto a outros, do atendimento de suas demandas ${ }^{20}$.

No presente estudo, 35,3\% dos entrevistados afirmaram que não discutem com seus pares as questões tratadas nas reuniões do CMS e muito menos transmitem as informações e/ou decisões para seus pares. Como forma de ilustração, destaca-se a fala de dois representantes dos usuários, quejustificam a não divulgação das informações:

As pautas vêm prontas, apenas para serem votadas, por isso elasnão são discutidas previamente.

N unca foi pedido pela instituição que represento.

Esse distanciamento entre representantes e representados foi encontrado também em outros estudos. Stralen et al. ${ }^{14}$, ao analisar a efetiva participação dos consel heiros de saúde, detectaram esse distanciamento ao indagar aos conseIheiros sobre como as necessidades dos usuários chegam ao conhecimento do conselho, sendo que apenas um dos representantes fez referência ao próprio segmento e às associações que representavam no CMS. 0 estudo de Guizardi e Pinhei$\mathrm{ro}^{5}$, por sua vez, também problematizou a concretização da representatividade, referindo nos seus resultados que a maioria dos conselheiros disse "sentir-se presença individual, e não institucional, no conselho".

Para Oliveira ${ }^{9}$, o debate éa expressão da pluralidade e uma forma de esforço e de ação para a emergência do que é público como expressão da potencialidade dos homens agindo em conjunto. Por esta razão, o poder não pode prescindir da comunicação, para construir e interferir no espaço público e organizar politicamente os interesses coletivos. Para alterar esse quadro, deve haver um deslocamento do poder de regiões verticais para regiões horizontais, possibilitando que segmentos sociais desprovidos de capacidade de intervenção possam participar de maneira mais concreta e ética na cena pública.

Nesse sentido, os resultados do presente estudo apontam para uma falta de interesse na participação e divulgação das propostas e discussões por partes dos gestores, representantes e representados, comprometendo, assim, a legitimidade destes junto ao CMS.

A comunicação entre os consel hos e a comunidadetem sido apontada como sendo um grande aspecto a ser aprimorado para incrementar o grau de representatividade desse fórum de participação social. No Brasil, ainda está sendo construída uma prática de participação cidadã, sendo muito comum, todavia, a não prestação de contas do representante para com seus representados, e os representados exercem pouco ou quase nada seu direito de cobrança em relação às ações dos representantes ${ }^{21}$.

Deve-se destacar que esse membros foram indicados ou eleitos por seus pares para os representá-los nos CM S. Como observado no es- 
tudo, $52,9 \%$ dos conselheiros relataram ter sido indicados por seus pares para comporem o CMS. Realidade semelhantefoi encontrada por M orita et al..$^{15}$ no município de Bertioga (SP), onde a maioria dos entrevistados ingressou no conseIho por indicação das suas entidades de classe, não considerando a necessidade de eleição. Este mesmo estudo concluiu que, ao invés de seguir um processo mais transparente e democrático, a eleição dos conselheiros acaba se transformando possivelmente num instrumento de manipulação política.

O conselheiro deve ter consciência da importância deseu papel representativo, entendendo que ele não representa interesses individuais e sim da coletividade. Daí a necessidade de existirem meios de comunicação e articulação entre os conselheiros e a sociedade para que haja, de um lado, a consulta, discussão e divulgação sobre o queétratado no CM S, garantindo a representatividade do conselheiro e, de outro, a visibilidade das atividades e deliberações e do Conselho na sociedade ${ }^{22}$.

N estemesmo sentido, M orita et al. ${ }^{15}$ afirmam que, em uma sociedade de classe, questões relacionadas ao conhecimento e poder continuam presentes, dificultando a participação dos desiguais. Uma série de obstáculos ainda se faz presente em função deuma história política caracterizada por regimes centralizadores e autoritários, que afastam os trabalhadores dos processos de tomada de decisão, dando origem a gerações de brasileiros que precisarão (re) aprender a participar da nova conjuntura social e política.

0 desenvolvimento de práticas democráticas efetivas pode fortalecer o controle social, uma vez que a participação não éum conteúdo quese possa transmitir, tampouco uma destreza que se possa adquirir pelo mero treinamento, mas, outrossim, uma mentalidade e um comportamento a ser construído pela reflexão crítica e pelo amadurecimento do cidadão. Compreendo que a participação popular éum processo quese constrói, diante da magnitude de criação deumanova cultura política democrática, em oposição à cultura de "exclusão" criada historicamentepelas elites dominantes em todo o país ${ }^{18}$.

Outro ponto estudado foi o relatório de gestão; segundo a Resolução n 333/2003, compete aos conselhos de saúde analisá-lo, discuti-lo e aprová-lo, com a prestação de contas e informações financeiras, repassadas em tempo hábil aos conselheiros, acompanhado do devido assessoramento. Cabe também ao CMS fiscalizar, controlar gastos e deliberar sobre critérios de movimentação do Fundo de Saúde ${ }^{13}$. Os resultados deste estudo apontam para o descumprimento da legislação vigente, o que consequentemente dificulta a atuação do CM S sobrea aplicação dos recursos financeiros, já que $29,4 \%$ dos entrevistados disseram que o CMS não recebe anualmenteo relatório de gestão da Secretaria M unicipal de Saúde para ser avaliado e aprovado, fato comprovado pelo próprio SM S ao afirmar que o relatório do ano de 2005 não foi elaborado. Vale ressaltar que cabe ao conselho solicitar, através desua mesa diretora, o cumprimento dessa questão pelo poder executivo municipal.

De todas as evidências aqui apresentadas, destaca-se a necessidade de esforços para possibilitar um sistema com corresponsabilidade, envolvendo gestores, profissionais de saúde, prestadores de serviço e usuários, no qual todos devem assumir uma postura com a "coisa pública", no sentido de dar maior visibilidade ao planejamento e avaliação das políticas de saúde ${ }^{16}$.

\section{Conclusão}

$\mathrm{Na}$ sociedade brasileira, os conselhos de saúde fazem partehistoricamentede um amplo processo de movimentação social, que desde a década de setenta vem convergindo para transformar e reconfigurar democraticamente o espaço público e a relação da sociedade civil com o Estado.

A análise da estrutura e da dinâmica de funcionamento do consel ho pesquisado aponta para al guns aspectos importantes ao campo do debate acerca da participação social em saúde: o processo de institucionalização do CM S, objeto deste estudo, limita a participação e o controle social, o que pode ser confirmado ao constatar-se que a composição do conselho não está de acordo com a legislação prevista - a maioria dos conselheiros não são eleitose sim indicados; as decisões e propostas não são divulgadas à população e muito menos aos pares dos consel heiros; 0 plano municipal de saúde está desatualizado e, por último, o relatório de gestão não é repassado anualmente. Todos estes aspectos dificultam a concreta e eficaz capacidade deintervenção dos conselheiros sobreas políticas eações implementadas no município.

Outrossim, os resultados aqui apresentados informam sobre a existência de dificuldade por parte dos representantes do poder executivo em partilhar o poder decisório nos espaços do conselho. Se, por um Iado, a sociedade civil tem 0 direito de participar das decisões políticas do setor saúde, por outro a desigualdade que marca 
as relações sociais em nosso país faz-se presente também nos conselhos de saúde, muitas vezes engessando a participação política dos grupos populares, mesmo onde essa presença se encontra juridicamente assegurada.

Essa relação assimétrica de poder, em que o espaço de deliberação política se faz inacessível e fragilizado, pode ter um efeito deburocratização dos conselhos, que deveser insistentementecombatida para que o conselho seja um espaço efetivamente democrático, legitimando os direitos conquistados pelos cidadãos.

Não obstante, vale ressaltar que, ao discutir os problemas encontrados neste estudo, não se pretendeu minimizar a importância do CMS de Viçosa para o município, mas sim identificar que os entraves estariam dificultando a concretiza- ção da participação social de forma mais ativa. Ao contrário, o que se pretende é colaborar para que o conselho funcione como um órgão de controle e de transparência nas decisões e ações do poder público. Neste sentido, é nossa proposta trabalhar na capacitação dos novos conselheiros, aproveitando a atual renovação deste CMS, instrumentalizando-os desta forma, para uma mais adequada participação e controle social.

Por fim, vale ressaltar que, apesar dos entraves apontados por diversos estudos sobre a efetivação do controle social, o conselho de saúde continua sendo espaço de participação da sociedade - fruto de uma longa luta democrática - e lugar de encontro de sujeitos sociais que, antes, estavam excluídos do jogo político e do processo de decisão.

\section{Colaboradores}

RM M Cotta foi a responsável pela coordenação, planejamento, orientação metodológica, acompanhamento do trabalho de campo, redação e revisão do artigo. M M Cazal trabal hou no delineamento do estudo, coleta dos dados, processamento, análise e interpretação dos dados, na redação e revisão do artigo. PC M artins participou da redação e revisão final do trabalho.

\section{Agradecimentos}

Os autores agradecem aos representantes do CMS participantes desse estudo, bem como à Secretaria Municipal de Saúde, por nos ter cedido os documentos necessários à pesquisa. 


\section{Referências}

1. Cotta RM M, Mendes FF, Muniz JN. Descentralização das Políticas Públicas de Saúde - do imaginário ao real. Viçosa: UFV; 1998.

2. Ribeiro JM. Conselhos de saúde, comissões intergestores e grupos de interesses no Sistema Único de Saúde (SUS). Cad Saude Publica 1997; 13(1):81-92.

3. Gerschman S. Conselhos M unicipais de Saúde: atuação e representação das comunidades populares. Cad Saude Publica 2004; 20(6):1670-1681.

4. Wendhausen A, Caponi S. O diálogo e a participação em um conselho de saúde em Santa Catarina, Brasil. Cad Saude Publica 2002; 18(6):1621-1628.

5. Guizardi FL, Pinheiro R. Dilemas culturais, sociais e políticos da participação dos movimentos sociais nos Conselhos de Saúde. Cien Saude Colet 2006; (11) 3:797-805.

6. Brasil. Constituição da República Federativa do Brasil. Brasília: Senado; 1988.

7. Presoto LH, Westhal MF. A participação social na atuação dos conselhos municipais de Bertioga - SP. Saude soc. 2005; 14(1):68-77.

8. Lei no 8.142 de 28 de dezembro de 1990. Dispõe sobre a participação da comunidade na gestão do Sistema Ú nico de Saúde (SUS) e sobre as transferências intergovernamentais de recursos financeiros na área da saúde e dá outras providências. Diário Oficial da União 1990; 28 dez.

9. Oliveira VC. Comunicação, informação e participação popular nos conselhos de saúde. Saude soc. 2004; 13(2):56-69.

10. Arendt H. A condição humana. São Paulo: Forense; 1995.

11. Instituto Brasileiro de Geografia e Estatística. Censo Demográfico de 2000. [CD-ROM ]. Rio de Janeiro: IBGE; 2000.

12. Programa das Nações Unidas para o Desenvolvimento, Instituto de Pesquisa Econômica Aplicada, Fundação João Pinheiro. Atlas do Desenvolvimento H umano no Brasil/Índice de Desenvolvimento Humano M unicipal. [site da Internet] Disponível em: http://www.ipea.gov.br/

13. Brasil. Resolução no 333, de 4 de novembro de 2003. A prova as diretrizes para criação, reformulação, estruturação e funcionamento dos conselhos de saúde. Diário Oficial da União 2003; 4 nov.
14. Van Stralen CJ, Lima AMD, Sobrinho DF, Saraiva LES, Van Stralen TBS, Belisário SA. Conselhos de saúde: efetividade do controle em municípios de Goiás e M ato Grosso do Sul. Cien Saude Colet 2006; 11(3):621-32.

15. Morita I, Guimarães JFC, Di Muzio BP. A participação de conselheiros municipais de saúde: solução que se transformou em problema? Saude soc. 2006; 15(1):49-57.

16. Assis M M A, Villa TCS. O Controle social e a democratização da informação: um processo em construção. Rev. Latino-Am. Enfermagem 2003; 11(3): 376-382.

17. Gohn MG. Papel dos conselhos gestores na gestão pública. Informativo Cepam 2002; 1(3):7-15.

18. Martins PCM. Controle social no Sistema Ú nico de Saúde: análise da participação social e empoderamento da população usuária do sistema sanitário [dissertação]. Viçosa (M G): Departamento de Nutrição e Saúde, Universidade Federal de Viçosa; 2007.

19. Westphal MF. Participação popular e políticas municipais de saúde: Cotia e Vargem Grande Paulista [dissertação]. São Paulo (SP): Faculdade de Saúde Pública; 1992.

20. Bosi MLM, Afonso KC. Cidadania, participação e saúde: com a palavra, o usuário da rede pública de serviços. Cad Saude Publica 1998; 14(2):355-365.

21. Serapioni M, Romaní O. Potencialidades e desafios da participação em instâncias colegiadas dos sistemas de saúde: os casos de Itália, Inglaterra e Brasil. Cad Saude Publica 2006; 22(11):2411-2421.

22. Correia MVC. Desafios para o controle social. Rio de Janeiro: Fiocruz; 2005.

Artigo apresentado em 27/06/2008

A provado em 27/06/2008

Versão final apresentada em 06/08/2008 